\title{
The effect of CYP450 2D6*4 mutation on medication response: Two cases with different outcomes
}

\author{
Yolande Lucire* \\ Forensic and medico-legal psychiatry, Pharmacogenomics and Personalized Medicine, Level 5, 203-233 New South Head Road, NSW 2027, Australia
}

\begin{abstract}
This paper describes different outcomes for genetically similar persons bearing the mutation CYP450 2D6*4. They were treated with the same drugs; their condition was called "schizophrenia" and in both cases the exclusion criterion essential for that diagnosis was ignored
\end{abstract}

Substance/general medical condition exclusion: The disturbance is not due to the direct physiological effects of a substance (e.g., a drug of abuse, a medication) or a general medical condition [1].

These cases support the notion that treatment of cannabis-induced disorders with drugs that have been tested for schizophrenia and bipolar illness may be counterproductive [2].

The paper highlights a need for doctors to diagnose to the criteria, and to be aware of (a) the DSM decision tree for the differential diagnosis of hallucinations, (b) the principles of pharmacogenetics, (c) the high prevalence of diminished metabolic capability for cytochrome P450 metabolised drugs, and (d) symptoms of neuroleptic toxicity, including akathisia $[3,4]$. It points to the need to seek advice from pharmacologists and pharmacogeneticists and not from peer clinicians who may also lack relevant expertise.

\section{Patient C}

C, 33, a university graduate, intermittently employed, had mild brain injury at birth and chicken pox encephalitis at 20. (Brain injury can cause akathisia and remains a risk factor for akathisia [5]. He smoked cannabis rarely. He was unable to say why he had been prescribed fluvoxamine by his general practitioner (GP). He soon developed a variant of erotomania (a side effect of all serotonergic antidepressants, reported thus in the Physicians' Desk Reference) in that he became preoccupied with a former girlfriend, ruminating on what might have been had he married her. He also harassed a friend of the former girlfriend, driving in his street and breaking windows [6].

Charged with a stalking offence, he presented for an s32 report under the NSW Mental Health (Criminal Procedure) Act 1990 that encourages diversion from the criminal justice system of persons suffering from a mental illness or condition. He was diagnosed with "paranoid schizophrenia," by his account in a 20-minute interview. Olanzapine was added to fluvoxamine and when he became increasingly depressed, restless and violently suicidal it was increased to $30 \mathrm{mg}$ daily while fluvoxamine was increased to $200 \mathrm{mg}$, and he continued to deteriorate. Zuclopenthixol depot was added to $200 \mathrm{mg}$ fortnightly and cigarette smoking increased to 40 a day. There was no improvement in his behaviour, so he was imprisoned on a certificate that called his illness schizophrenia but held him responsible for his actions [7].
On release, he continued to drive obsessively in his quarry's street (indicative of both organic obsessional disorder and erotomania) and was about to be imprisoned again on his treating psychiatrist's certificate attesting to his intentionality, when he made a suicide attempt and was hospitalised with deep vein thrombosis [8]. He had $35 \mathrm{mg}$ diazepam daily added but it gave no relief. Warfarin was added to the above for the deep vein thrombosis. Zuclopenthixol was suspended in hospital.

The author diagnosed akathisia and erotomania and wrote a Section 32 report, and this avoided his receiving a second prison sentence. Four years later, fully recovered, on no medication and showing no sign of schizophrenia and working in three jobs, $\mathrm{C}$ described his mental state at that earlier time:

I figured I had nothing to live for. I was feeling like I had no future and I did not want 40 more years of this. I thought of hanging myself or slashing my wrists. I do not know how often. I also thought of crashing into a truck or jumping in front of a train. I was never suicidal before I had fluvoxamine. I smoked heaps.

I had the injection because I thought it would keep me out of jail.

I could not sit and read, I could not focus on anything, I was restless, and I could not sit down. The last five days in jail were hard. I could not sleep at all, that carried on after I went out of jail. I could not do anything, could not sit down and watch TV. I had to get up and pace around, a hundred times a night. After I got out of jail, the world completely changed. Home to me has always been a haven. For those eight months, I had hell inside.

On legal advice, the author advised C's mother that three psychiatrists, one of whom was a personal friend of $\mathrm{C}$, shared her view that he had did not have schizophrenia or anything like it. His mother researched akathisia on the Internet and requested a change of doctor in view of a total breakdown of the doctor/patient relationship.

${ }^{\star}$ Correspondence to: Yolande Lucire, Forensic and medico-legal psychiatry, Pharmacogenomics and Personalized Medicine, Level 5, 203-233 New South Head Road, NSW 2027, Australia, Tel: 0411158246, E-mail: lucire@ozemail.com.au

Received: August 07, 2018; Accepted: October 25, 2018; Published: October 31,2018 
Frustrated by administrative inaction, the mother made a complaint to the Medical Board of NSW (MBNSW), which declined to investigate it. However, the Board chose instead to pursue the author for holding this allegedly minority view through a Professional Standards Committee (PSC).

The PSC found the author to have "inappropriately" destroyed the mother's confidence in the treating doctor, notwithstanding that the mother gave evidence that she and her son had none. The author was criticised for having insufficient respect for the diagnoses of her colleagues and this was based on peer reviews, of peers who did not acknowledge product information (PI).

The PSC unilaterally, without giving notice, decided to publish its report where no such PSC matters had ever before been publicised. The author was publicly humiliated as having "insufficient knowledge" and as lacking respect for her colleagues' diagnoses. This decision was based on the author's holding what the PSC considered to be a "minority view" concerning antidepressant side effects and interactions, even though four files of evidence that antidepressants induced psychosis and suicide in some people were provided, together with PI and relevant public health advisories. The MBNSW recommended that the author seek the counsel of a colleague. The decision was misreported in The Sun Herald to the effect that the author had been "ordered into treatment by the Medical Board".

$\mathrm{C}$ was allowed to reduce all his medications slowly. Four years later, $\mathrm{C}$ works in three jobs and shows no signs of schizophrenia. He is stigmatised by his criminal record and traumatised by the experience of the painful mental state of some duration, but relieved to know that he had suffered from a medication side effect rather than a mental illness.

\section{Patient A}

While a 16-year-old schoolboy in 2004, smoked cannabis, used other illicit drugs and experienced hallucinations. He was prescribed risperidone and deteriorated [11]. Olanzapine was added at both variable and increasing doses. This produced worsening depression and continuing hallucinosis. Fluvoxamine was added, and he became violently suicidal.

Soon added in series and parallel were benztropine, haloperidol, chlorpromazine, lithium, risperidone and its depot, consta, quetiapine; previously ineffective treatments were recirculated in escalating doses.

Patient A remained violently akathisic, intensely suicidal, aggressive and intermittently homicidal. He was seen tramping along the motorway at night in the rain before he made a homicidal attack on his stepfather in 2005. He spent four months in an interstate clinic. $\mathrm{He}$ assaulted his psychiatrist in January 2006 and was imprisoned.

He made many suicide attempts and repeatedly complained that his medication made him feel suicidal. His unremitting death wish was recorded as "I cannot function on this medication. It makes me want to kill myself". He continued to smoke cannabis, insisting it helped him, and his tobacco use increased [10].

Zuclopenthixol depot was reinstated in prison at $400 \mathrm{mg}$ fortnightly in the face of his protests and history. After his release it was increased to $600 \mathrm{mg}$ on one occasion and enforced by a Community Treatment Order (CTO).

His penultimate suicide attempt from a cliff a day after his release from hospital on a CTO caused police to return him to hospital where the diagnosis of schizophrenia was amended to "antisocial personality".
Two days later and after 4 years of treatment, he was found dead at the bottom of the same cliff, in December 2006. No root cause analysis was provided for the relatives.

The coroner gave the author very limited access to clinical records and treatment sheets and refused permission to make copies. He determined, on a report from police, that A had not committed suicide at all but had been "skylarking". On that basis, he declined to hear expert evidence prepared for an inquest and did not respond to a suggestion that genetic testing for CYP450 activity was needed. The issue of the coroner perhaps having a conflict of interest was raised with both the Chief Coroner and the Judicial Commission because, as a magistrate, the coroner had previously been involved with A and because he was involved with that health service on a daily basis. Both found that no conflict existed.

\section{Commentary}

CYP450 testing revealed that both patients had a "null" metaboliser gene $2 \mathrm{D} 6^{\star} 4$ (in the case of $\mathrm{A}$, after exclusion of his parents' genotypes).

Both had received multiple interacting drugs that compete for CYP450 2D6, a metabolising resource that is finite and may be limited by genotype or P450 inhibitors or other health problems. When a metabolic pathway is already in limited supply, lower doses are recommended because the drug is likely to reach blood levels above the "therapeutic window of opportunity' for each drug" [11].

Both polypharmacy (endemic in Australian psychiatry) and the use of higher than recommended doses are counterproductive. Akathisia and other organic neurotoxic states supervene, and patient does not recover. Standard doses of a single substrate accumulate in diminished metabolizers and lead to blood levels higher than the therapeutic window. The concurrent use of Cytochrome P450 inhibitors hastens that process. More frequent dosing than permitted by the half-life of each drug results sooner or later in neurotoxic state and hallucinatory delirium.

Both $\mathrm{C}$ and A were taking, simultaneously, several drugs requiring the 2D6 pathway, in larger than recommended doses: olanzapine at 30 $\mathrm{mg}$ daily is 15 times the normal starting dose, fluvoxamine $200 \mathrm{mg}$ is 4 times, zuclopenthixol injections at $600 \mathrm{mg}$ fortnightly is 8 times the standard dose. Eli Lilly does not guarantee the safety of olanzapine over $20 \mathrm{mg}$.

The notion that patients who have not responded to antidepressants are ultra-rapid metabolizers (UMs) underpins the practice of increasing a medication or adding another. However, it is many times more likely that such patients are poor (PMs) or diminished metabolizers (DMs), and as such need to have the dose decreased. From 5\% to $14 \%$ of Caucasians are PMs of 2D6 and a further 20\% have diminished metabolism. PMs may experience potentially lethal side effects within days, whereas the slower metabolism of intermediate metabolizers (IMs) causes a slow build-up of blood level while the chemistry of the brain tries to follow. Rapid changes of psychoactive substances cause violent mood and behavioural shifts, confusion and delirium in IMs. UMs comprise only 1-10\% of Caucasians [12].

If a patient on psychotropic medication develops symptoms of delirium or of akathisia, every psychiatry textbook I have been able to identify advises dose reduction or change of medication to one more suited to the patient. The problem occurs on change of dose up or down and has been associated along with other extra pyramidal side effects, as well as sensitivity. 
Akathisia is a subjective desire to be in constant motion. A manifestation of drug sensitivity, it may be confused with psychotic agitation and incorrectly treated by increasing the dose of the offending medication. The symptom subsides promptly when the offending medication is discontinued and replaced by another one better tolerated by the patient [13].

The subjective distress resulting from akathisia is significant and can lead to non-compliance with neuroleptic treatment. Akathisia may be associated with dysphoria, irritability, aggression or suicide attempts. Worsening of psychotic symptoms or behavioral dyscontrol may lead to an increase in neuroleptic medication dose, which may exacerbate the problem. Akathisia can develop very rapidly after initiating or increasing neuroleptic medication [14].

Substrates of 2D6 also include tricyclics, tetracyclics, amphetamines, chlorpromazine (which has other pathways as well), fluvoxamine, haloperidol, risperidone, quetiapine and, in part, olanzapine.

Cannabis, involved in both these cases, is metabolised by cytochromes 3A4, 2B6 and 2C9. It is an inhibitor of 3A4 and induces 1A2. It remains in the body for up to 2 months, depending on the amount used. Like tobacco, which induces IA2 and caffeine induces the metabolism of psychiatric drugs as well as producing is own euphoric neurotoxic state $[15,16]$.

\section{Pharmacogenetics}

Pharmacogenetic theory and data provide an arena in which adverse drug reactions can be explored, understood, theorised and ultimately predicted [17]. The development of pharmacogenetics has ushered in a paradigm shift of massive proportions in medicine and, particularly, psychiatry. It is predictable that this shift is resisted [18].

Pharmacogenetics has featured in American textbooks of psychiatry since 1999, but it has not been taught in Australia until very recently [19]. Australia is the last of the U.K., Canada and the U.S. to inquire into the potential of pharmacogenomics, by means of a report that, unaccountably, expects a lead period of 10 years to full implementation [20]. "One size does not fit all" appears to be its theme.

Delay in implementing this education will result in more hospital admissions for adverse drug events, already a major source of costs in the U.S., as well as prolonged stays, misdiagnoses and unnecessary deaths and medication-induced suicides and homicides [21-24]. No psychiatrist can practise safely without this knowledge.

It may be that lack of this knowledge accounts for psychiatry's insatiable demand for resources, and for the increasing suicides, suicide attempts, homicides and violence committed by patients under mental health care $[25,26]$. Providing more resources for psychiatry without questioning the source of this epidemic of seemingly intractable mental ill health is unlikely to resolve the problem $[27,28]$.

\section{Metabolic pathways}

Nearly $90 \%$ of drugs are metabolised by the cytochrome CYP450 family of enzymes, 1000 enzymes determined by 40 genes [29]. They transform "exotoxins" into products that can be metabolised further (stage II metabolism) and prepared for excretion by the kidney or liver. Diminished capacity to metabolise drugs results in blood and brain levels above the sometimes-narrow therapeutic window. These concentration-dependent adverse effects manifest as neurotoxic

Table 1. Drugs metabolic pathways, inducers and inhibitors (of drugs used in these cases) from several sources [30]

\begin{tabular}{|c|c|c|c|c|}
\hline Drug & Therapeutic window [31] & Metabolism/transport site & Enzymes/process inhibited & Enzymes Induced/ \\
\hline chlorpromazine & $30-300 \mathrm{ng} / \mathrm{ml}$ & 2D6, 1A2, 3A4, UGT1A4, UGT1A3 & $2 \mathrm{D}^{\mathrm{a}}$ & \\
\hline clomipramine & $175-450 \mathrm{ng} / \mathrm{ml}$ & $1 \mathrm{~A} 2,2 \mathrm{C} 19,2 \mathrm{D} 6,3 \mathrm{~A} 4$ & 2D6, 1A2, 2C19 & \\
\hline cannabis & & $3 \mathrm{~A} 4,2 \mathrm{~B} 6$ and $2 \mathrm{C} 9$. & $3 \mathrm{~A} 4$ & $1 \mathrm{~A} 2$ and $2 \mathrm{E} 1$ \\
\hline carbamazepine & $6-12 \mu \mathrm{g} / \mathrm{ml}$ & $\begin{array}{l}\text { 3A4, 2B6, 2C8, 2E1, 2C9, 1A2, UGT2B7, } \\
\text { ABCB1 }\end{array}$ & $? 2 \mathrm{C} 19$ & $\begin{array}{l}\text { 3A4, 1A2, 2B6, 2C8, 2C9, } \\
\text { UGT1A4 }\end{array}$ \\
\hline clonazepam & $20-40 \mathrm{ng} / \mathrm{ml}$ & 3A4, acetylation & & \\
\hline clozapine & $350-600 \mathrm{ng} / \mathrm{ml}$ & $1 \mathrm{~A} 2,3 \mathrm{~A} 4,2 \mathrm{D} 6,2 \mathrm{C} 9,2 \mathrm{C} 19, \mathrm{FMO}_{3}$ & $2 \mathrm{D} 6^{\mathrm{c}}$ & \\
\hline diazepam & $300-400 \mathrm{ng} / \mathrm{ml}$ (incl. metabolites) & 3C19, 3A4, 2B6, 2C9, glucuronidation & & \\
\hline doxepin & $50-150 \mathrm{ng} / \mathrm{ml}$ & 1A2, 2D6, 2C19, 3A4, UGT1A4, UGT1A3 & $1 \mathrm{~A} 2,2 \mathrm{C} 19,2 \mathrm{D} 6$ & \\
\hline fluphenazine & $0.5-2 \mathrm{ng} / \mathrm{ml}$ & $2 \mathrm{D}^{\mathrm{a}}, 1 \mathrm{~A} 2$ & 2D6 $6^{\mathrm{a}}, 1 \mathrm{~A} 2$ & \\
\hline clopixol & $>2 \mathrm{ng} / \mathrm{ml}$ & 2D6 & & \\
\hline fluvoxamine \# & $150-300 \mathrm{ngms} / \mathrm{ml}$ & 2D6, 1A2 & $1 \mathrm{~A} 2^{\mathrm{a}}, 2 \mathrm{C} 19^{\mathrm{a}}, 2 \mathrm{~B} 6^{\mathrm{b}} 3 \mathrm{~A} 4^{\mathrm{b}}, 2 \mathrm{D} 6^{\mathrm{b}}, \mathrm{ABCB} 1$ & \\
\hline haloperidol & $5-17 \mathrm{ng} / \mathrm{ml}$ & 2D6 & & \\
\hline lithium & $0.5-1.2 \mathrm{mmol} / 1$ & & & \\
\hline lorazepam & $10-15 \mathrm{ng} / \mathrm{ml}$ & UGT2B7, ?other UGTs & & \\
\hline olanzapine \# & $\begin{array}{l}\text { half-life } 21-54 \text { mean } 30 \text { hrs. } 9-25 \\
\text { ngms } / \mathrm{ml} \mathrm{[32]} \\
100 \mathrm{ngms} / \mathrm{ml} .\end{array}$ & $\begin{array}{l}\text { 1A2, } 1 \mathrm{~A} 4 \text { partly by } 2 \mathrm{D} 6 \text { and UGT3A4, } \\
\text { UGTs, ABCB } 1\end{array}$ & None known & \\
\hline paliperidone \# & & ? 2D6, 3A4 & None known & \\
\hline perphenazine & $0.6-2.4 \mathrm{ng} / \mathrm{ml}$ & 2D6, 3A4, 1A2, 2C19 & 2D6, 1A2 & \\
\hline quetiapine \# & $70-170 \mathrm{ng} / \mathrm{ml}$ & 3A4, sulfation, $\mathrm{ABCB} 1$ & & \\
\hline risperidone & 20-60 ng/ml (including 9-hydroxy) & 2D6, 3A4, ABCB1 & $2 \mathrm{D} 6^{\mathrm{b}}$ & \\
\hline risperidone consta & ditto & ditto & ditto & \\
\hline temazepam & & UGT2B7,? other UGTs, 2C19, 3A4 & & \\
\hline valproate & $50-100 \mu \mathrm{g} / \mathrm{ml}$ & $\begin{array}{l}\text { Complex: 2C9, 2C19, 2A6, UGT1A6, 1A9, } \\
\text { 2B7 }\end{array}$ & 2D6, 2C9, UGTs, 1A4, 1A9, 2B7, 2B15, epoxide & \\
\hline zuclopenthixol & $4-50 \mathrm{ngms} / \mathrm{ml}$ & 2D6 & $\begin{array}{l}\text { ? 2D6 (European drugs are less well researched than } \\
\text { those used in the U.S.) }\end{array}$ & \\
\hline
\end{tabular}

a Potent inhibition of enzymatic pathway. ${ }^{\mathrm{b}}$ Moderate inhibition ${ }^{\mathrm{c}}$ Mild inhibition. Inhibition is also dose-related; mild inhibitors in high doses act as strong inhibitors. \# Not licensed for use in children or adolescents by the United States Food and Drug Administration (FDA) or its Australian equivalent, the Therapeutic Goods Administration, (TGA. 
brain syndromes. Many psychiatric patients are prescribed more than one drug, with each drug increasing the risk of a pharmacokinetic interaction. Table 1 shows metabolic pathways inducers and inhibitors, and it has been brought up to date from primary sources.

There is an argument that patients would benefit from CYP-based genotyping prior to the prescription of these drugs. Up to $79 \%$ of islanders from around Vanuatu have PM status at 2C19 and around $25 \%$ of Caucasians have "diminished metabolism," at 2D6, and for them a drug metabolised by that pathway is likely to be or becomes problematic and might be lethal [33]. East Asians have a 50\% prevalence of the IM gene P2D6*10, as well as up to $35 \%$ prevalence of the PM gene $2 \mathrm{C} 19^{\star} 2$, putting that population at a huge risk from antidepressant therapy. Testing for CYP450 2D6, 2C19 and 2C9 costs less than \$150.

Basic knowledge of the ethnicity-based prevalence of mutations is essential to counter a common belief among psychiatrists that worsening depression and suicidality in a patient indicate a lack of response, and that the patient is therefore a UM. Such reasoning leads to more and more medication being given. In fact UMs are rare, often cited in Caucasian populations as $3 \%$.

Most adverse drug reactions occur as a result of simple over-dosing of genetically normal persons whose cytochrome metabolism has been inhibited or induced, leading to undesirable bloods levels. There are six patterns of drug-drug interactions and some are described below [34]. The first effect of making testing available might be to make prescribers aware that adverse drug events are both explicable and avoidable.

Conditions affecting metabolism include co-prescribed medications that induce or inhibit the enzymatic pathways, age, nutrition, stress, liver disease, hormones (natural and extraneous), the sequence in which medications have been prescribed or taken away, the route of administration, the range of half-life in any population, the potential for multiple metabolic pathways, the size of the therapeutic window within which the drug may be effective and outside of which it is ineffective or toxic or both, the duration of therapy and duration of inhibition which may persist after discontinuation [35]. This paper does not deal with the genetics of transporter and receptor systems.

3A4 is the "workhorse" of the P450 system, which means that many drugs are substrates of it, and there are many inhibitors and inducers. There are no PMs but there is $10-30$-fold variability in the efficacy of its functioning. 1A2 metabolises psychiatric drugs and is induced by tobacco smoking, which also hastens the metabolism of other psychiatric medicines not known to be metabolised by these cytochromes. This seems to explain why patients on psychiatric medications increase their tobacco use: to more quickly metabolise medicines that have unpleasant or intolerable adverse effects.

Information grows and changes daily. All three are involved in the metabolism of common antidepressants and antipsychotics [36].

Table 2 is compiled from research done by health insurers Blue Cross Blue Shield who have found such testing to be cost effective. The table lists the effects of genetic polymorphisms of CYP450 enzyme genes on drug metabolism and describes relationships between genotype and phenotype, as relevant for psychiatric drugs, many of which inhibit the enzymes required for their metabolism [37-39]

A more useful concept adopted by the Diversity Health Institute (DHI) at Cumberland Hospital is to describe both PMs and IMs as having "diminished CYP 450 metabolism". This is because the inhibition or absence of one cytochrome may divert into metabolism by others, which may or may not be available in any given individual. There can be $1,000 \%$ variance in the metabolism of 2D6 drugs between PMs and UMs and a 30 -fold variance in metabolism by the enzyme cytochrome $3 \mathrm{~A} 4$ [44].

Table 2. Genotypes phenotypes and predictions

\begin{tabular}{|c|c|c|c|c|c|c|}
\hline Metaboliser status & $\begin{array}{l}\text { Metaboliser } \\
\text { status }\end{array}$ & $\begin{array}{l}\text { Metaboliser } \\
\text { status }\end{array}$ & Genotype & Phenotype & Expected drug effects & Prodrug concerns \\
\hline 2D6 & $2 \mathrm{C} 9$ & $2 \mathrm{C} 19$ & & & & 2D6 \\
\hline $\begin{array}{l}\text { PM } \\
\text { (poor) *3, *4, } \\
* 4 \mathrm{XN}, \\
* 5, * 6, * 7, * 8, \\
* 11, * 15, * 19, \\
* 20, * 40\end{array}$ & $\begin{array}{l}\mathrm{PM} \\
* 2 \text { and } * 3\end{array}$ & $\begin{array}{l}\text { PM } \\
* 2, * 3\end{array}$ & $\begin{array}{l}\text { PM Homozygous or } \\
\text { compound heterozygous } \\
\text { for deficiency alleles. }\end{array}$ & PM & $\begin{array}{l}\text { "Standard" doses may lead } \\
\text { to toxic drug concentrations } \\
\text { and serious adverse reactions, } \\
\text { including suicide and } \\
\text { homicidal behaviours }[40] .\end{array}$ & $\begin{array}{l}\text { May not reach therapeutic levels of } \\
\text { active drug, i.e. does not convert } \\
\text { prodrugs into the analgesic morphine, so } \\
\text { they are ineffective. Conversely removal } \\
\text { of a 2D6 inhibitor may lead to rapid } \\
\text { conversion and toxicity and death (the } \\
\text { Heath Ledger phenomenon) }\end{array}$ \\
\hline $\begin{array}{l}\text { IM (intermediate) } \\
* 10, * 10 \mathrm{XN}, \\
* 17, * 17 \mathrm{XN}, \\
* 9, * 29, * 36, \\
* 41, * 41 \mathrm{XN}\end{array}$ & $\begin{array}{l}\text { IM } \\
* 1 \text { and } * 2 \\
\text { or } * 3 \\
\text { or } * 3 / * 3\end{array}$ & & $\begin{array}{l}\text { IM } \\
\text { Homozygous for } \\
\text { two reduced activity } \\
\text { enzyme genes alleles } \\
\text { or heterozygous for an } \\
\text { inactive allele and a } \\
\text { reduced activity allele. }\end{array}$ & $\begin{array}{l}\text { These may become PMs or } \\
\text { diminished metabolisers in the } \\
\text { presence of specific inhibitors. }\end{array}$ & $\begin{array}{l}\text { A reduced dose of a single drug } \\
\text { is recommended, and IMs are } \\
\text { unable to metabolise multiple } \\
\text { drugs requiring that pathway. } \\
\text { Higher doses may lead to toxic } \\
\text { levels. }\end{array}$ & $\begin{array}{l}\text { May experience some consequences } \\
\text { of PMs. }\end{array}$ \\
\hline $\begin{array}{l}\text { EM (extensive) } \\
\text { "wild type" } \\
* 1, * 2, * 35\end{array}$ & $\begin{array}{l}\text { EM } \\
* 1, * 1\end{array}$ & $\begin{array}{l}\text { EM } \\
19 * 17[41]\end{array}$ & $\begin{array}{l}\text { Two copies of active } \\
\text { enzyme gene alleles. }\end{array}$ & $\begin{array}{l}\text { Up to } 80 \% \text { of EMs at } 2 \mathrm{D} 6 \\
\text { become PMs in the course } \\
\text { of treatment with strong } \\
\text { inhibitors such as paroxetine } \\
\text { [42], fluoxetine and sertraline } \\
\text { and with mild inhibitors in } \\
\text { high doses. }\end{array}$ & $\begin{array}{l}\text { Standard doses lead to } \\
\text { expected drug concentrations } \\
\text { and response. }\end{array}$ & Expected response to standard dose. \\
\hline $\begin{array}{l}\text { UM (ultra-rapid) } \\
\text { Only 2D6 has } \\
\text { UMs *AXON, } \\
\text { *2XN, } \\
\text { *35XN }\end{array}$ & & & $\begin{array}{l}\text { More than two active } \\
\text { copies of active enzyme } \\
\text { gene alleles. }\end{array}$ & & $\begin{array}{l}\text { May not reach therapeutic } \\
\text { levels of active drug due to } \\
\text { rapid clearance. }\end{array}$ & $\begin{array}{l}\text { May reach higher than expected } \\
\text { concentrations of active metabolite, } \\
\text { which may cause adverse reactions, } \\
\text { including death from morphine. }\end{array}$ \\
\hline
\end{tabular}

Notes: Genotype refers to the genetic makeup of the subject; phenotype refers to the way that the genotype manifests under a variety of conditions [43].

$\mathrm{PM}=$ poor metabolizer; $\mathrm{IM}=$ intermediate metabolizer; $\mathrm{EM}$ = extensive metabolizer; $\mathrm{UM}=$ ultrarapid metabolizer. Prodrugs such as tramadol, oxycodone, codeine need to be activated, i.e. catabolised to morphine by $2 \mathrm{D} 6$. 
Mutation P450 2D6*4 was found in more than one third of 30 persons tested at the author's request because they had experienced severe violent akathisia, suicidal behaviours, homicidal aggression, behavioural dyscontrol, delirium with hallucinosis, and cognitive impairment on standard doses of antidepressants (to be reported elsewhere). The most publicised of these is Melbourne mother and student Rebekah Beddoe, who published her harrowing account of three years on antidepressants and antipsychotics, prescribed and coprescribed by psychiatrists who failed to recognise her problems as side effects [45].

\section{Drugs relevant to these two cases}

\section{Olanzapine}

Side effects are listed in each drug's PI, easily accessible through the website of the U.S. FDA [46]. PI published in the U.S. is substantially larger and more detailed than that available in Australia. It categorises "frequent" adverse events as occurring in at least $1 / 100$ patients, "infrequent" events as occurring in 1/100 to $1 / 1000$ patients and "rare" events as occurring in less than $1 / 1000$.

By that standard, in clinical trials that were presented to the U.S. FDA to get olanzapine licensed, death and suicide on olanzapine occurred at a rate of 1 in 208, which is "rare." No deaths occurred on placebo. Khan et al. counted the suicides in antipsychotic trials 2001 but this paper failed to alert the psychiatric community [47].

A rate of $27 \%$ akathisia in a trial of olanzapine $10 \mathrm{mg}$ was balanced by an equally high incidence of akathisia on placebo [49]. This indicated that Eli Lilly either did not know what they were talking about (as akathisia is always a medication-induced phenomenon), or the participants had not fully recovered from whatever they had been taking before entry to the trial. This been the subject of successful litigation for fraudulent promotion of olanzapine, such as USA vs. Eli Lilly which rewarded the whistleblowers with US $\$ 800$ million [50].

The half-life of olanzapine ranges from 21 to 54 hours (5th to 95th percentile; mean of $30 \mathrm{hr}$ ), and apparent plasma clearance ranges from 12 to $47 \mathrm{~L} / \mathrm{hr}$ (5th to 95 th percentile; mean of $25 \mathrm{~L} / \mathrm{hr}$ ). This means that sooner or later more than $50 \%$ of users will become toxic on it if the dose is not reduced. The half-life and clearance of olanzapine varies among individuals on the basis of smoking, status, gender and age.

According to Eli Lilly Australia the therapeutic window of olanzapine is $9-25 \mathrm{ngm} / \mathrm{ml}$, but other figures are mentioned elsewhere [51].

In drug company terms, "frequent" refers to adverse events affecting more than $10 \%$ of users. The following effects are listed in the 2007 Olanzapine PI. (Olanzapine is licensed for bipolar disorder.)

Nervous System - Frequent: abnormal dreams, amnesia, delusions, emotional lability, euphoria, manic reaction, paresthesia and schizophrenic reaction;

Infrequent: akinesia, alcohol misuse, antisocial reaction, ataxia, CNS stimulation, cogwheel rigidity, delirium, dementia, depersonalization, dysarthria, facial paralysis, hypesthesia, hypokinesia, hypotonia, incoordination, libido decreased, libido increased, obsessive compulsive symptoms, phobias, somatization, stimulant misuse, stupor, stuttering, tardive dyskinesia, vertigo, and withdrawal syndrome;

Rare: circumoral paresthesia, coma, encephalopathy, neuralgia, neuropathy, nystagmus, paralysis, subarachnoid hemorrhage, and tobacco misuse.
Australian PI is incomplete, but it does inform that hallucinations are "very common" ( $\geq 10 \%)$. That is, they occur in more than 1 in 10 users.

Eli Lilly was fined \$US 1.42 billion in the United States for criminal and fraudulent promotion of the drug, with the judge raising the issue of racketeering [51]. There are many lawsuits, settled and ongoing, against Eli Lilly by State Attorneys General, as well as class actions for suicides. With Eli Lilly reaping US $\$ 6$ billion annually from olanzapine, these fines and settlements are apparently insufficient to encourage the company to change its promotional practices and have made no impact on the behaviour of the company in Australia.

Four major studies (HGAD, E00, HGAJ and E003) were reviewed by the U.S. FDA for the purpose of establishing the efficacy of olanzapine in the treatment of chronic schizophrenia (acute exacerbation). According to the U.S. FDA reviewers, the studies failed to establish any significant effectiveness for olanzapine. Two thirds of clinical trial subjects dropped out without completing 6 weeks. Even after they dropped out, 20 died, 12 by suicide. Concomitant drugs were permitted in these trials.

American PI also discloses that 67 of 3,100 subjects (including a trial rejected by the U.S. FDA) took overdoses of olanzapine, but it is silent on whether these patients were considered to be suicidal or confused. As "only one" died (of the overdose) these numbers are put forward as evidence of olanzapine safety in overdose. However, a courtordered investigation of Eli Lilly archives disclosed the deaths and suicides in the five clinical trials that were presented to the US FDA to get it licensed [52]. The figures are shown in Tables 3 and 4.

One in every 145 clinical trial subjects for risperidone, olanzapine, quetiapine, and sertindole died, a total of 36 deaths, most by suicide [53]. Yet these deaths are not mentioned in the scientific literature nor in PI. These deaths occurred even though two thirds of the olanzapine subjects, nearly half of the risperidone subjects and $80 \%$ of the quetiapine subjects did not complete the trials because the drugs were poorly tolerated [54]. A rate of $27 \%$ akathisia in a trial of olanzapine 10 mg was reported, balanced by an equally high incidence of akathisia on placebo [55]. This indicated that Eli Lilly either did not know what they were talking about (as akathisia is by definition a medicationinduced phenomenon), or the participants had not fully recovered from whatever they had been taking before entry to the trial. Serious adverse events affected 84 subjects who took risperidone.

None of this information appears in promotional material. Indeed, 47 serious adverse events in 87,000 users of olanzapine injectable in

Table 3. Incidence of suicides and suicide attempts in antipsychotic clinical trials drawn from U.S. FDA license applications [48]

\begin{tabular}{|c|c|c|c|}
\hline Drug & $\begin{array}{c}\text { Number of Trial } \\
\text { Subjects }\end{array}$ & Suicides & Suicidal Acts \\
\hline Olanzapine & $\begin{array}{c}\text { 2500(5000 started } \\
\text { and did not complete } \\
\text { 6-week trials })\end{array}$ & 12 & Not disclosed\# \\
\hline Comparator & 810 & $1(2)$ & Not disclosed \\
\hline Placebo & 236 & $0(1)$ & Not disclosed \\
\hline
\end{tabular}

\# However, U.S. PI (2003) states that 67 subjects out of 3100 overdosed on olanzapine but does not disclose if these overdoses were due to suicide attempts or delirium, and "only 1 died".

Table 4. Antipsychotic Drugs, FDA Trials: Source FDA, David Healy [64]

\begin{tabular}{|c|c|c|c|}
\hline Drug & Patient No. & Suicides & Suicidal Acts \\
\hline Risperidone & 2607 & 9 & 43 \\
\hline Comparator & 601 & 1 & 5 \\
\hline Placebo & 195 & 0 & 1 \\
\hline
\end{tabular}


clinical trials included eight deaths. We are assured that the deaths were not related to the olanzapine but, given the number of suicides and deaths associated with the oral preparation, this seems to be improbable. The U.S. FDA issued a "black box" warning about sudden death from the new antipsychotic medications (including quetiapine and aripiprazole) but only for the elderly, in spite of evidence that all age groups are adversely affected [56,57].

\section{Fluvoxamine}

Fluvoxamine is metabolised by $2 \mathrm{D} 6$ and $1 \mathrm{~A} 2.1 \mathrm{~A} 2$ is induced by cannabis and tobacco, so smoking both gives relief from toxicity. Fluvoxamine is best described as a pan inhibitor as it is a potent inhibitor of $1 \mathrm{~A} 2$ and 2C19 and a mild to moderate inhibitor of 2B6, $2 \mathrm{C} 9$ and $3 \mathrm{~A} 4$. Fluvoxamine was used in both $\mathrm{A}$ and $\mathrm{C}$ with olanzapine, in the face of advice against this combination in PI.

Fluvoxamine, a CYP1A2 inhibitor, decreases the clearance of olanzapine. This results in a mean increase in olanzapine Cmax following fluvoxamine of $54 \%$ in female nonsmokers and $77 \%$ in male smokers. The mean increase in olanzapine Area Under the Curve (AUC) is 52\% and $108 \%$, respectively. Lower doses of olanzapine should be considered in patients receiving concomitant treatment with fluvoxamine.

Fluvoxamine was the drug prescribed to one of the children who perpetrated the Columbine High School massacre. Most school massacres have been perpetrated by children taking prescribed antidepressants or medications for ADHD [58].

\section{The "atypical" antipsychotics: Risperidone and Consta, its depot}

Risperidone is metabolised by 2D6, has a shorter half-life than olanzapine and may need twice daily administration. In trials presented to the U.S. FDA, two thirds of subjects did not complete. Those subjects have never been mentioned in PI or the scientific literature, but this information is available at www.lillytrials.com and was summarised by Grace Jackson for litigation against Eli Lilly in Alaska [59]. None of the dropout rates, suicides and attempts is disclosed to prescribers and patients. As a result, treating doctors, not knowing or expecting these drugs to be poorly tolerated because they were misinformed about clinical trials, organise for Mental Health Review Tribunals to enforce them, by injection, to persons who cannot tolerate them orally, as happened with Patient C. Coroners, if not willing to examine the activities of hospitals where they are deployed several times a week, can create a situation where regulatory agencies cannot be made aware of this epidemic.

The FDA trials and 52 subsequent studies evaluated in 2000, by John Geddes of Oxford University demonstrated no clear evidence that atypical antipsychotics were more effective or better tolerated than conventional antipsychotics [60]. Thirty-six, that being one in every 145 clinical trial subjects for Risperdal, Zyprexa, Seroquel,) and Sertindole died; most by suicide, yet these deaths are never mentioned in scientific literature or prescriber information. These deaths occurred even though two thirds of Zyprexa, nearly half the Risperdal and $80 \%$ of Seroquel subjects did not complete the trials because the drugs were poorly tolerated [61]. A rate of $27 \%$ akathisia in a trial of Zyprexa $10 \mathrm{mg}$ was balanced by an equally high incidence of akathisia on placebo [62]. This indicated that Eli Lilly either did not know what they were talking about (as akathisia events including suicide and homicide are always a medication-induced adverse drug event or, alternately, the participants had not fully recovered from whatever they had been taking before entry to the trial. Serious adverse events affected 84 subjects who took Risperdal.

\section{Zuclopenthixol decanoate}

Zuclopenthixol depot has been associated with mental health homicides, but invariably in combination, with other drugs that are substrates of 2D6, as in the two cases presented here. The author has personal experience of admitting patients homicidal on zuclopenthixol, often co-prescribed with antidepressants and atypical (new generation) antipsychotics. Several reports of this combination causing violent attacks and homicidal behaviours were dismissed by the MBNSW, and her report about patient $\mathrm{C}$ was turned into a complaint about her. As did patients $\mathrm{C}$ and $\mathrm{A}$ here, many were experiencing akathisia, with homicidal as well as suicidal ideation and acts [63-65].

The half-life of the zuclopenthixol depot preparation is 19 days, so if it is given fortnightly, toxicity will eventually develop.

\section{Summary}

Patients $\mathrm{C}$ and $\mathrm{A}$ are but two of 48 people from the author's clinical and medico legal practice for 2D6, 2C9 and 2C19. Of the people tested, 42 were found to be poor or intermediate metabolizers and the rest were overmedicated by PI standards. They were tested because they experienced violent, homicidal and suicidal akathisia on standard doses of antidepressants; one of them committed suicide, most had made many attempts and three committed homicide on single doses of antidepressants after 3 days, 2 weeks and 6 weeks on drugs that genetic studies showed they could not metabolise; none of these three had a psychiatric illness before or since, nor any history of violence. Only six had normal CYP450 cytochromes, but they had either been given large doses or had inhibitors in play. They had experienced many years of counterproductive psychiatric treatments.

In the decade a following the introduction of the first of these drugs, fluoxetine, in 1990, the population under mental health care in Australia doubled and it has continued to increase. This is reflected in Australian psychiatry's vastly increased demands for resources [66]. Many 'second generation' drugs have followed this. The treatment of schizophrenia with new drugs has increased mortality so care needs to be taken before that diagnosis is applied, along with its remedies [67-69]. Patients C and A are typical of persons under mental health care who were not schizophrenic before they used drugs or received treatment that induced symptoms similar to those of schizophrenia. Yet testing for CYP450 mutations is available, for $\$ 140.00$. That is the start of appropriate personalised medicine.

\section{Cannabis, its metabolites and 2D6}

Cannabinols are metabolised by P3A4 and also inhibit it while inducing 1A2. Sohayla et al. investigated the role of genetic factors in cannabis dependence (hashish smokers) by CYP $2 \mathrm{D}^{\star} 4$ genotyping of 46 habituated volunteers. Their findings suggest that genetic factors may determine a person's attraction to the effects of cannabis and other illicit substances, but the mechanism is not obvious from existing research. Diminished metaboliser status may cause cannabis to be experienced as pleasurable, and if so, a propensity to substance-induced mood disorder is a possibility. Cannabis smokers are said to have a tendency to become psychotic later in life, but the mechanism is also obscure. Drug clinics generally yield higher proportions of diminished metabolizers, for reasons that have not yet been researched.

The common mislabelling of cannabis effects and other toxic states as schizophrenia mania, major depression or bipolar disorder 
is counterproductive. The diagnostic criteria for all those disorders contain an exclusion criterion for substance or medication use. Misdiagnosis of mental and behavioural disorders as being attributable to psychoactive substance use appears to contribute to the furphy that cannabis causes schizophrenia.

Clinical prescriptions are available at F10-F19 "Mental and Behavioural Disorders due to psychoactive substance" of the ICD 10, still Australia's official diagnostic system.

\section{Drug clinic and cannabis users}

The role of diminished P450 metabolism, specifically $2 \mathrm{D} 6^{\star} 4$, in cannabis smokers and the prevalence of mutations in drug clinic populations generally bear further examination. One possibility is that in diminished metabolism, 2D6 capacity may increase both the pleasurable effects of cannabis and maybe other drugs and the tendency to medication-induced psychotic phenomena. It may be that they are already taking medication and are using cannabis to moderate it. Suspicion of a high prevalence of diminished metabolizers at 2D6 among cannabis smokers might caution against the use of medicines demand that substrate.

Misdiagnosis of mental and behavioural disorders due to psychoactive substance use appears to contribute to the furphy that cannabis causes schizophrenia.

Although ecological studies report an increase in schizophrenia and bipolar illness, detailed analysis of such cases suggests that the population that becomes psychotic on cannabis also develops neurotoxic syndromes on olanzapine and risperidone, as well as antidepressants, particularly those metabolised by $2 \mathrm{D} 6$.

\section{References}

1. Diagnostic and statistical manual of mental disorders: DSM IV (1992) Washington DC: American Psychiatric Association 1994. And ICD International Statistical Classification of Diseases and Related Health Problems ICD 10. Tenth Edn. Geneva: World Health Organization.

2. DSM-IV-TR® Handbook of differential diagnosis (2007) Ch. 2. Differential diagnosis by the trees american psychiatric publishing.

3. De Leon, J Scott, Armstrong Cozza, K1 Med-Psych (2006) Drug-drug interactions update. Clinical guidelines for psychiatrists for the use of pharmacogenetic testing for CYP450 2D6 and CYP450 2C19 Psychosomatics 47:1.

4. Sachdev P (1995) Akathisia and restless legs, Cambridge University Press. Cambridge.

5. Physicians Desk Reference Oradell New Jersey: Medical Economics Company 2003.

6. Hálfdánarson Ó, Zoëga H, Aagaard L, Bernardo M, Brandt L, et al. (2017) International trends in antipsychotic use: A study in 16 countries, 2005-2014. Eur Neuropsychopharmacol 27: 1064-1076. [Crossref]

7. Teicher MH, Glod CA, Cole JO (1993) Antidepressant drugs and the emergence of suicidal tendencies. Drug Saf 8: 186-212. [Crossref]

8. de Leon J, Susce MT, Pan RM, Fairchild M, Koch WH, et al. (2005) The CYP2D6 poor metabolizer phenotype may be associated with risperidone adverse drug reactions and discontinuation. J Clin Psychiatry 66: 15-27. [Crossref]

9. Zullino DF, Delessert D, Eap CB, Preisig M, Baumann P (2002) Tobacco and cannabis smoking cessation can lead to intoxication with clozapine or olanzapine. Int Clin Psychopharmacol 17: 141-143. [Crossref]

10. Bauman P, Hiemke C, Ulrich S, Eckermann G, Gaertner I (2004) The ANGP-TDM expert group consensus guidelines: therapeutic drug monitoring in psychiatry. Pharmacopsychiatry 37: 243-265. [Crossref]

11. Ingelman-Sundberg M (2005) Genetic polymorphisms of cytochrome P450 2D6 (CYP2D6): clinical consequences, evolutionary aspects and functional diversity. Review. Pharmacogenomics 5: 6-13.

12. Kaplan HI, Saddock BJ, Freedman AM (1980) Comprehensive textbook of psychiatry. Baltimore: Wilkins and Wilkins.
13. Diagnostic and statistical manual of mental disorders (DSM-IV) (1994) American Psychiatric Association. Drug Induced Akathisia.

14. Cannabis is metabolised by $3 \mathrm{~A} 4,2 \mathrm{~B} 6$ and $2 \mathrm{C} 9$. It is an inhibitor of $3 \mathrm{~A} 4$ and induces 1A2. It remains in the body for up to two years depending on how much was used.

15. Shirley KH, YY Penzak, SR Lam, YWF Spratlin, V Jann MW (2003) Correlation of cytochrome P450 (CYP) 1A2 activity using caffeine phenotyping and olanzapine disposition in healthy volunteers. Neuropsychopharmacology 28: 961-966.

16. Cozza KL, Armstrong SC, Oesterheld JR (2003) Drug interaction principles for medical practice: cytochrome P450s, UGTs, P-Glycoproteins. Arlington, Va, American Psychiatric Publishing.

17. Refinetti R (1997) Philosophy of science and physiology education. Am J Physiol 272 S31-35. [Crossref]

18. Hales R, Yudofsky S, Talbot, JA (1999) Textbook of psychiatry. Third ed. Washington DC: The American Psychiatric Press

19. Improving the quality use of medicines in Australia: Australian centre for health research realising the potential of pharmacogenomics (2008).

20. Lazarou J, Pomeranz BH, Corey PN (1998) Incidence of adverse drug reactions in hospitalized patients: a meta-analysis of prospective studies. JAMA 279: 1200-1205. [Crossref]

21. Schulte JL (1985) Homicide and suicide associated with akathisia and haloperidol American Journal of Forensic Psychiatry 6: 3-7.

22. Healy D, Herxheimer A, Menkes DB (2006) Antidepressants and violence: problems at the interface of medicine and law. PLoS Med 3: e372. [Crossref]

23. Breggin PR (2003) Suicidality, violence, and mania caused by selective serotonin reuptake inhibitors: A review and analysis. Ethical Human Sciences \& Services 5: 225246.

24. Yolande Lucire (2005) New Drugs, New Problems. Australian Journal of Forensic Sciences 37: 19-25.

25. NSW Mental Health Sentinel Events Committee. Tracking Tragedy: A systemic look at suicides and homicides amongst mental health inpatients (2004).

26. Healy D, Whitaker C (2003) Antidepressants and suicide: risk-benefit conundrums. $J$ Psychiatry Neurosci 28: 331-337. [Crossref]

27. Whitaker R (2005) Anatomy of an epidemic: psychiatric drugs and the astonishing rise of mental illness in America. Ethical human psychology and psychiatry. An International Journal of Critical Inquiry 7: 23-35.

28. Tanaka E, Hisawa S (1999) Clinically significant pharmacokinetic drug interactions with psychoactive drugs: antidepressants and antipsychotics and the cytochrome P450 system. Journal of Clinical Pharmacy \& Therapeutics 24: 7-16.

29. Oesterheld, JR Cozza, K Armstrong SC, Neil B Sandson (2007) Drug-drug interactions: a compendium of case vignettes for the practicing clinician. American Psychiatric Publishing

30. Letter from Eli Lilly Australia, cf Bauman, opp cit.

31. Communiqué: mayo reference services. Cytochrome P450 enzyme genotyping optimizing patient care through pharmacogentics. September 2005.

32. Armstrong SC, Cozza KL, Sandson NB (2003) Six patterns of drug-drug interactions Psychosomatics 44: 255-258. [Crossref]

33. http://medicine.iupui.edu/flockhart/table.htm; and http://www.pharmgkb.org

34. Sandson NB (2007) Drug-drug interactions primer. A compendium of vignettes for the practicing clinician. American Psychiatric Press.

35. Blue Cross Blue Shield Association (2004) Special report: genotyping for cytochrome P450 polymorphisms to determine drug-metabolizer status. Technology Assessmen Program 19: 1-34.

36. https://www.labcorp.com/pdf/Cytochrome_P450_2C9_LabCapsule.pdf

37. https://www.labcorp.com/pdf/gen_Cytochrome_P450_2C9_LabCapsule.pdf

38. Cassidy vs. Eli Lilly http://www.prozactruth.com/prozaccases.htm also http://www. namiscc.org/News/2002/Fall/ProzacSuitSettled.htm

39. Wynn GH, Oesterheld, JR Cozza, K, Armstrong SC (2009) Clinical Manual of Drug Interaction Principles for Medical Practice. American Psychiatric Publishing Inc.

40. Zourkova A, Hadasova E (2003) Paroxetine-induced conversion of cytochrome P450 2D6 phenotype and occurence of adverse effects. General Physiology \& Biophysics 22: $103-113$. 
41. Cozza KL, Armstrong SC, Oesterheld JR (2003) Drug Interaction principles for Medical Practice. American Psychiatric Publishing Inc

42. ibid.

43. Beddoe Rebekah (2006) Dying for a Cure, Random House.

44. http://www.accessdata.fda.gov/scripts/cder/drugsatfda/index.cfm

45. Khan A, Khan SR, Leventhal RM, Brown WA (2001) Symptom reduction and suicide risk among patients treated with placebo in antipsychotic clinical trials: an analysis of the food and drug administration database. Am J Psychiatry 158: 1449-1454. [Crossref]

46. Healy D (2004) Shaping the intimate: influences on the experience of everyday nerves. Soc Stud Sci 34: 219-245. [Crossref]

47. http://www.lillytrials.com

48. http://www.usdoj.gov/opa/pr/2009/January/09-civ-038.html

49. Personal Correspondence with Eli Lilly signed Vicky Foster B Nursing (2008) Letter states Please note that currently olanzapine therapy is not approved for general use in adolescent patients.

50. http://www.pharmalot.com/2008/10/lilly-to-take-14-billion-charge-for-olanzapineprobe.

51. http://americanfraud.com/tmapfraud.aspx

52. Whitaker Robert (2002) Mad in America Perseus publishing.

53. Harris G (2005) Popular drugs for dementia tied to deaths. The New York Times.

54. FDA Public health advisory: Deaths with antipsychotics in elderly patients with behavioural disturbances.

55. http://www.ssristories.com/ for these and other "SSRI" suicides.

56. http://psychrights.org/states/Alaska/CaseOne/30-Day/ExhibitD-Olanzapine.
57. Geddes J (2000) Atypical antipsychotics in the treatment of Schizophrenia: A systematic overview and meta-regression analysis. BMJ 321: 1371-1376.

58. Whittaker Robert (2002) Mad in America Perseus Publishing (2002)

59. Harris G (2005) Popular drugs for dementia tied to deaths. The New York Times.

60. Shear MK, Frances A, Weiden P (1983) Suicide associated with akathisia and depot fluphenazine treatment. Journal of Clinical Psychopharmacology 19: 235-236.

61. Schulte J (1985) Homicide and Suicide associated with akathisia and halperidol. American Journal of Forensic Psychiatry 6: 3-7.

62. Schulte JL (1985) Treatment of the mentally disordered offender. American Journal of Forensic Psychiatry 6: 29-36.

63. Greenland H (2003) Dying Shame. The Bulletin This is reflected in a demand for beds and resources.

64. Joukamaa M, Heliövaara M, Knekt P, Aromaa A, Raitasalo R (2006) Schizophrenia, neuroleptic medication and mortality. British Medical Journal 188: 122-127.

65. Joukamaa M, Heliövaara M, Knekt P, Aromaa A, Raitasalo R, et al. (2006) Schizophrenia, neuroleptic medication and mortality. Br J Psychiatry 188: 122-127. [Crossref]

66. McGrath J, Saha S, Chant D, Welham J (2008) Schizophrenia: a concise overview of incidence, prevalence, and mortality. Epidemiologic Reviews 30: 67-76.

67. de Leon J, Armstrong SC, Cozza KL (2006) Clinical guidelines for psychiatrists for the use of pharmacogenetic testing for CYP450 2D6 and CYP450 2C19. Psychosomatics 47: 75-85. [Crossref]

68. M Attalla Sohayla ZE-SA, El-Baz Ayman (2008) Genetic polymorphism of cytochrome P450 -2d6*4 In Cannabis Smokers. 2008. Volume 5 Number genetic polymorphism of cytochrome P450 -2d6*4 In Cannabis Smokers. The Internet Journal of Toxicology 5: 68 .

Copyright: (C2018 Lucire Y. This is an open-access article distributed under the terms of the Creative Commons Attribution License, which permits unrestricted use, distribution, and reproduction in any medium, provided the original author and source are credited. 